\title{
Factors influencing tackle injuries in rugby union football
}

\author{
W M Garraway, A J Lee, D A D Macleod, J W Telfer, I J Deary, G D Murray
}

\begin{abstract}
Objectives-To assess the influence of selected aspects of lifestyle, personality, and other player related factors on injuries in the tackle. To describe the detailed circumstances in which these tackles occurred.
\end{abstract}

Methods-A prospective case-control study was undertaken in which the tackling and tackled players ("the cases") involved in a tackle injury were each matched with "control" players who held the same respective playing positions in the opposing teams. A total of 964 rugby matches involving 71 senior clubs drawn from all districts of the Scottish Rugby Union (SRU) were observed by nominated linkmen who administered self report questionnaires to the players identified as cases and controls. Information on lifestyle habits, match preparation, training, and coaching experience was obtained. A validated battery of psychological tests assessed players' trait anger and responses to anger and hostility. The circumstances of the tackles in which injury occurred were recorded by experienced SRU coaching staff in interviews with involved players after the match.

Results-A total of 71 tackle injury episodes with correct matching of cases and controls were studied. The following player related factors did not contribute significantly to tackle injuries: alcohol consumption before the match, feeling "below par" through minor illness, the extent of match preparation, previous coaching, or practising tackling. Injured and non-injured players in the tackle did not differ in their disposition toward, or expression of, anger or hostility. Some $85 \%$ of tackling players who were injured were three quarters, and $52 \%$ of injuries occurred when the tackle came in behind the tackled player or within his peripheral vision. Either the tackling or tackled player was sprinting or running in all of these injury episodes. One third of injuries occurred in differential speed tacklesthat is, when one player was travelling much faster than the other at impact. The player with the lower momentum was injured in $80 \%$ of these cases. Forceful or crunching tackles resulting in injury mostly occurred head on or within the tackled player's side vision.

Conclusions-Attention should be focused on high speed tackles going in behind the tackled player's line of vision. Comparative information on the circumstances of the vast majority of tackles in which no injury occurs is required before any changes are considered to reduce injuries in the tackle. (Br F Sports Med 1999;33:37-41)

Keywords: personality; player characteristics; prevention; rugby; tackle; injury

The tackle is the phase of play that produces the highest proportion of injuries in rugby union football. ${ }^{1-3}$ Tackle injuries result in 56\% of all playing or training days lost to the game as well as $61 \%$ of all work days away from employment or education. ${ }^{4}$ Previous studies have focused on the nature of injuries arising from tackles, but have not provided detailed information on the circumstances of the tackles themselves. Only a few studies in sports medicine have looked at the personal characteristics of participants, mainly in running related injuries. $^{5-7}$ There are no published reports of the influence of personal lifestyle, personality, or other player related factors on rugby injuries. The aims of this study are to assess the importance of these factors in tackle injuries and to report the detailed circumstances of the tackles in which the injuries occurred.

Methods

Scottish Rugby Union (SRU) development officers assisted in the selection of senior Scottish rugby clubs from all districts of the SRU who were asked to participate in the survey. An experienced linkman was appointed at each club, who, after receiving training, was responsible for completing all match details including whether or not a tackle injury episode had occurred. A tackle injury episode was defined as an incident during which a player carrying the ball on the field of play was "tackled" by one or more opponents resulting in the injured player missing the remainder of the match. Attempted, late, and off the ball tackles were included. Details of only the first tackle injury episode in any one match were recorded. Tackling in rugby matches often involves more than one player. Therefore the principal tackler was identified as that person who was mainly responsible for making the tackle, or contributed the most direct or the greatest force or momentum to the tackle.

The reasons why injuries occur in the tackle may include the playing circumstances in which the tackle occurs and/or personal factors associated with the players involved. An estimate of the risk of these factors present in either the principal tackling or tackled player, either of whom might have contributed to the injury episode, 
required that similar information was obtained from players who were not involved in the injury episode. Thus both the principal tackler and the tackled players (the "cases") were matched with two other players participating in the match (the "controls"). Control players held the same respective positions in opposing teams as did the two players involved in the tackle injury episode. For example, where a right wing three quarter tackled an opposition inside centre, the right wing three quarter and inside centre from the opposite teams were identified as the control players.

The risk was estimated using the odds ratio - that is, the odds of injury in exposed players divided by the odds of injury in unexposed players. The pairing of cases and controls was retained in the analysis. With one control player for each tackle player, the observations were divided into four categories: $(a)$ where both tackle and control player were exposed to the suspected risk factor; $(b)$ where the tackle player was exposed but the control player was not exposed to the suspected risk factor; $(c)$ the tackle player was not exposed but the control player was exposed; (d) neither the tackle player nor the control player was exposed to the suspected risk factor. If the odds ratio was greater than 1.00 , then the factor being examined would have an adverse effect, i.e. could be contributing to injuries occurring in the tackle. If on the other hand, the odds ratio was less than 1.00 , the suspected risk factor may have a protective effect on tackle injuries. An odds ratio of 1.00 meant that the suspected risk factor would have had a neutral effect on tackle injuries.

In matches in which tackle injury episodes occurred, the principal tackling and tackled players (the cases) and their matched controls were each given an information pack at the end of the match by the club linkman. Information on a range of personal characteristics and lifestyle habits of the players was sought. Informed consent to participate in the survey was obtained. A validated psychological questionnaire assessed players' disposition towards anger and their typical responses to anger and hostility. ${ }^{8}$ The development officers of the SRU telephoned the principal tackler and tackled player as soon as possible after the match to obtain information about the circumstances of the tackle in which the injury occurred. The position of tackle injury episodes on the field of play was obtained using grid references which divided the pitch up into plots of $5 \mathrm{~m}^{2}$.

Information on 964 senior club rugby matches (including 136 cancelled matches) was obtained from the linkmen representing the 71 senior rugby clubs who participated in the survey during the 1996-1997 season. Eighty two matches contained a tackle injury episode that met all the criteria adopted for the study. Insufficient documentation was available for eight of these matches, and three additional matches were not included in the analysis because of incorrect matching of the players involved in the tackle with their controls. Thus the case-control analysis used 71 injury episodes, whereas the analyses of the detailed circumstances of the tackle used 72 injury episodes. In one of these, both players were injured. Information on the speed with which players were travelling at the time of the tackle and the force of the tackle itself were obtained on a scale of 1 (least speed or force) to 5 (greatest speed or force). A score of 4 in the speed scale was the equivalent of running; 5 represented sprinting. Similarly, a score of 4 on the force scale of a tackle was described as forceful, and 5 was a crunching tackle. Tackles were classified as: head on to the tackled player; in his side vision (from 0 to $30^{\circ}$ and 330 to $359^{\circ}$; in peripheral vision (between 31 and $60^{\circ}$ and 300 and $329^{\circ}$ and in blind vision (from 61 to $299^{\circ}$ ). In considering response differences between the principal tackler and tackled player about the circumstances of the tackle, precedence was given to the information provided by the tackling player.

\section{Results}

PLAYER CHARACTERISTICS

Table 1 sets out the odds ratios and $95 \%$ confidence intervals for factors that might have contributed to tackle injuries when comparing the injured player with his control, namely players' lifestyle, feeling "below par", match

Table 1 Comparison of selected characteristics of players injured in the tackle with their matched controls

\begin{tabular}{|c|c|c|c|c|c|c|}
\hline \multirow[b]{2}{*}{ Player characteristics } & \multicolumn{4}{|c|}{ Number of matched pairs } & \multirow[b]{2}{*}{ Odds ratio } & \multirow[b]{2}{*}{$95 \% C I$} \\
\hline & ++ & +- & -+ & -- & & \\
\hline \multicolumn{7}{|l|}{ Personal risk factors } \\
\hline Drinking alcohol in 24 hour period before a match & 9 & 16 & 24 & 22 & 0.67 & $0.32-1.37$ \\
\hline $\begin{array}{l}\text { Not wearing contact lenses in match when he normally } \\
\text { requires contacts/glasses }\end{array}$ & 1 & 10 & 10 & 50 & 1.00 & $0.35-2.87$ \\
\hline \multicolumn{7}{|l|}{ Feeling below par } \\
\hline Suffering from minor illness before a match & 0 & 5 & 10 & 56 & 0.50 & $0.12-1.80$ \\
\hline Had interrupted sleeping night before a match & 4 & 12 & 13 & 41 & 0.92 & $0.36-2.33$ \\
\hline Taking medicine at the time of the match & 0 & 5 & 8 & 58 & 0.63 & $0.15-2.43$ \\
\hline \multicolumn{7}{|l|}{ Match preparation } \\
\hline Not attending rugby training weekly & 3 & 3 & 4 & 61 & 0.75 & $0.09-5.32$ \\
\hline Insufficient warm up before match & 1 & 5 & 9 & 56 & 0.56 & $0.13-2.07$ \\
\hline \multicolumn{7}{|l|}{ Rugby coaching } \\
\hline Never coached on tackling & 0 & 2 & 5 & 64 & 0.40 & $0.03-2.99$ \\
\hline Not practised tackling & 0 & 9 & 7 & 55 & 1.29 & $0.39-4.41$ \\
\hline $\begin{array}{l}\text { Never received information on minimising risk of tackle } \\
\text { injury }\end{array}$ & 0 & 14 & 20 & 37 & 0.70 & $0.31-1.53$ \\
\hline \multicolumn{7}{|l|}{ Team stability } \\
\hline Recently promoted to team & 3 & 10 & 8 & 50 & 1.25 & $0.41-3.92$ \\
\hline Not playing in his usual position & 3 & 11 & 11 & 46 & 1.00 & $0.37-2.71$ \\
\hline
\end{tabular}

++, Both case and control exposed; +-, only case exposed; -+, only control exposed; --, neither case nor control exposed. 
A

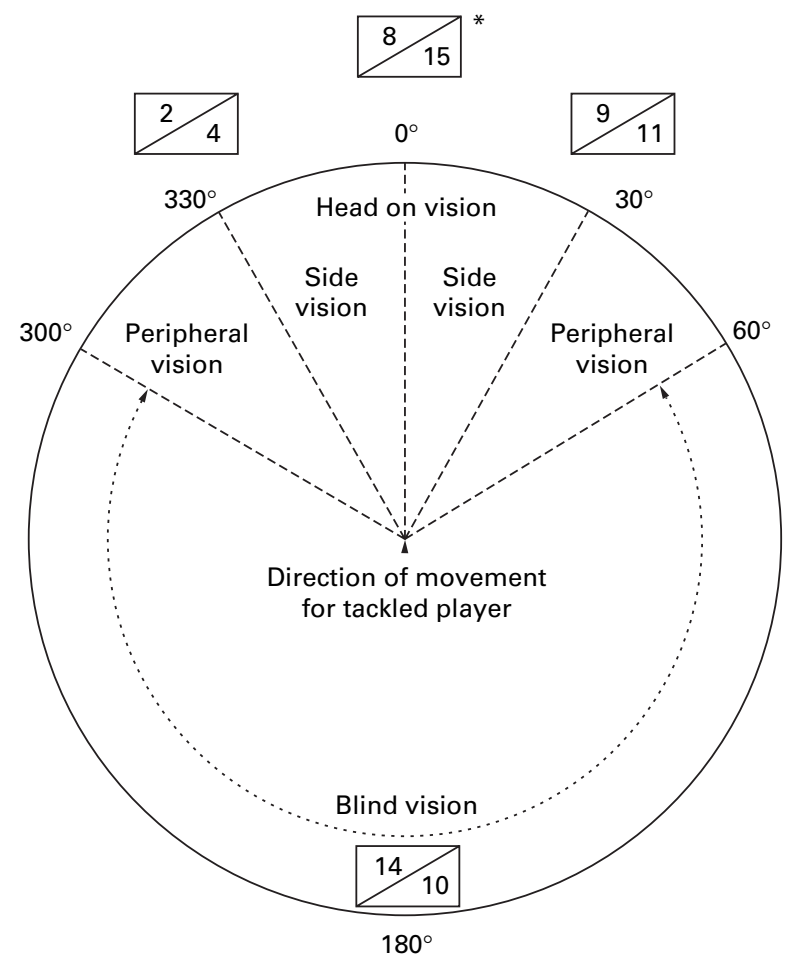

B

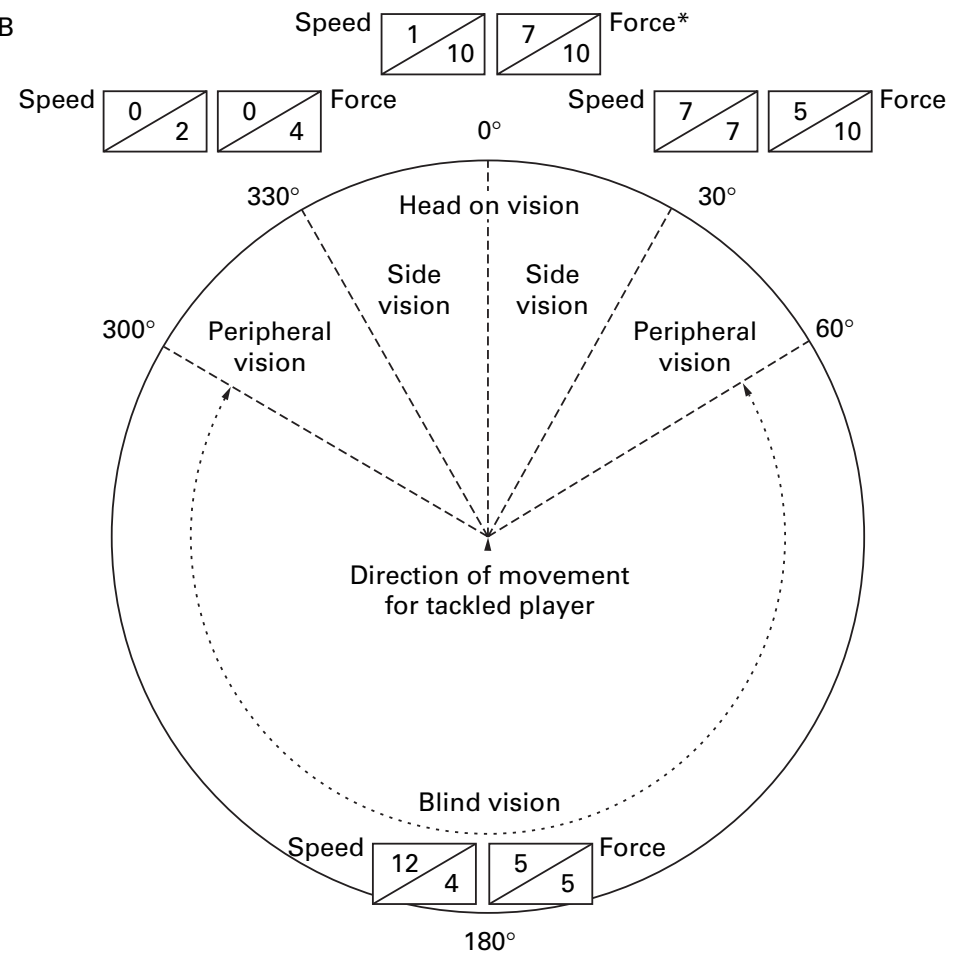

Figure 1 (A) Number and direction of tackles in which an injury episode occurred and (B) number of injury episodes in which the players involved were either running or sprinting and the tackles were either forceful or crunching. The number in the left hand side of each box is the number of tackling players injured, and that in the right hand side of each box is the number of tackled plavers. ${ }^{\star}$ Includes one tackle injury episode in which both players were injured. The tackling player's report of the direction of the tackle was given preference when player's views differed.

preparation, the influence of rugby coaching, and players' team stability. None of the factors has a significant effect on tackle injuries in an adverse or protective way. Confidence intervals are wide throughout, in part as a consequence of the small number of matched pairs of players used in the analysis. None of the variables from the Spielberger state trait anger inventory (STAXI) were significantly different between the injured and non-injured players. ${ }^{8}$ There was no evidence of differences between injured players and their controls in their tendency towards general feelings of anger or in their modes of anger expression.

NATURE AND SITE OF TACKLE INJURIES

Information on the detailed circumstances of tackles was available for 72 tackle injury episodes. The tackled player alone was injured in 39 cases, the principal tackler in 32 cases, and both were injured in one tackle injury episode. No less than $85 \%$ (28/33) of principal tackling players injured were three quarters. Only $26 \%$ (19/72) of tackle injury episodes involved forwards who tackled other forwards. Some $30 \%(22 / 73)$ of injuries were to the lower limb, predominantly knee ligament strains, sprains, and ruptures. Concussion was present in $12 \%$, and shoulder dislocations occurred in a further 12 injury episodes (16\%). Twenty seven of the 144 players (19\%) in the tackle stayed on their feet or were supported on their feet in the tackle by other team members. Of those injured players who fell to the ground as a result of the tackle, seven of 12 tackled players and five of seven tackling players who landed on their shoulders injured this part of their body.

DIRECTION, SPEED, AND FORCE OF THE TACKLE Figure 1(A) illustrates the direction in which tackles resulting in injury episodes came, as seen from the direction of movement of the tackled player. Overall $31 \%$ (22) of tackle injuries occurred head on, with a further $17 \%$ (12) within the player's right or left sided vision. More than half $(52 \%)$ of all the tackles in which injuries occurred came from within the tackled player's peripheral vision $(19 \%)$ or from behind him (33\%). Surprisingly, in situations where tackled players were completely blinded, the tacklers came off worse. Some $25 \%(10 / 40)$ of all injuries to tackled players occurred in their blind vision, whereas $42 \%$ (14/33) of all tackling player injuries occurred in tackles made from behind the tackled player. Tackles resulting in injury were three times more frequent on the right side of the tackled player than the left. Figure 1(B) presents the number of injury episodes where involved players were either running or sprinting; or when the tackle was forceful or crunching according to the direction in which the tackle was made. About $61 \%$ (20/33) of injuries to the tackling player occurred at running or sprinting speeds, and 23 tackled players were injured while travelling at running or sprinting speeds, from behind their line of vision $(17 \%)$, head on $(43 \%)$, or in right sided vision $(30 \%)$ tackles. Either the tackled or principal tackler were sprinting or running in all injuries that occurred outside the tackled player's range of vision. Injuries occurring in tackles described as forceful or crunching were predominantly in head on $(38 \%)$ or right sided vision $(31 \%)$, particularly when tackled players were injured. 


\begin{tabular}{|l|}
\hline - Injured player in \\
the home team \\
- Injured player in \\
the away team
\end{tabular}

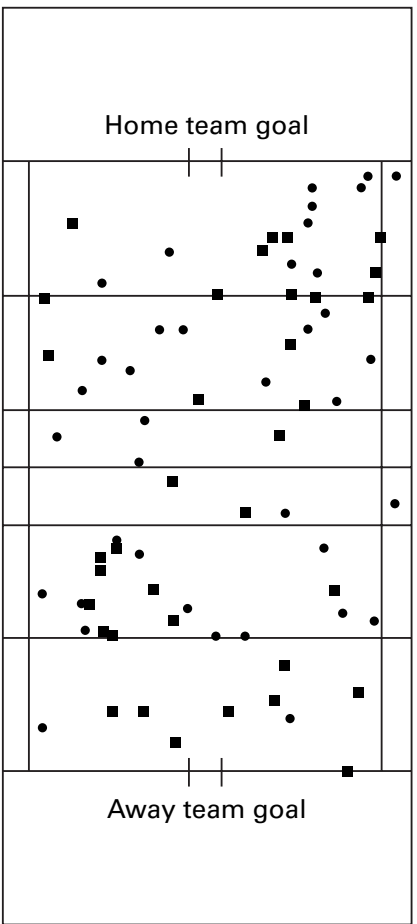

Figure 2 (A) Position on the field of play where the tackle injury episode occurred, according to whether the player was in the home or away team and (B) the speed of players involved in tackle injury episodes, according to their occurrence on the field of play.

NATURE AND TYPE OF TACKLE

Only 35\% (14/40) of tackles when the tackled player was injured and $21 \%(7 / 33)$ when the principal tackling player was injured were described as "big hits". About $19 \%$ of tackle injury episodes involved multiple players and a further $18 \%$ were described as "smother" tackles. Around $71 \%(15 / 21)$ of tackled players who were injured as a result of a "big hit" were three quarters. Tackled players often were not aware of the type of tackle made on them, because a high proportion of tackles occurred in their blind or peripheral vision. However, from the tackling player's view, $60 \%$ of tackles were classical; a further $25 \%$ were attempted but not complete; $8 \%$ were late tackles and only the remaining five tackles in which injuries occurred were described as "off the ball". Either the tackled player or the tackler was moving at running or sprinting speeds in $91 \%$ of classical tackles.

POSITION ON THE FIELD OF PLAY

The position of tackle injury episodes on the field of play was obtained using grid references which divided the pitch up into plots of $5 \mathrm{~m}^{2}$. In $88 \%$ of cases $(63 / 72)$, there was agreement between the players about the site of the tackle to within $10 \mathrm{~m}^{2}$. Figure 2(A) illustrates the position of the field of play where each of the 72 tackle injury episodes occurred, according to whether the injured player was playing in the home (34) or away team (37); in one tackle, both players were injured. Overall, 26 (36\%) of injury episodes occurred within the $22 \mathrm{~m}$ zones, but 18 (69\%) of these injuries occurred to players attacking their opponent's goal line. Only five tackles were within the $5 \mathrm{~m}$ line. Sixteen of the 18 attacking players injured in their opponents' $22 \mathrm{~m}$ line were tacklers; the remaining two injuries occurred in tackles by their opponents coming out of defence. There are further differences in tackle injuries in relation to their position on the field of play, according to their speed or momentum at impact in the tackle. This is summarised in fig 2(B). This divides tackle injuries into (a) those that occurred at maximum speed (in which both the tackled and tackling players were travelling at running or sprinting speeds on impact), (b) injuries that occurred when players were travelling at very different speeds - that is, there was a difference of at least two grades in the five point speed scale between the tackling or tackled players-and (c) intermediate speed tackles comprising the remainder of tackles. Some $44 \%(32 / 72)$ of tackle injuries occurred with both players travelling at maximum speed at impact, and 35\% (25/72) were differential speed tackles in which either the tackler or the tackled player was stationary or travelling much more slowly at impact. The player standing still or with the lower momentum was injured in $80 \%(20 / 25)$ of all differential speed tackles. Some $62 \%$ (16/ 26) of all tackles in the $22 \mathrm{~m}$ zones were at maximum speed. The distribution of differential speed tackles were evenly divided between the $22 \mathrm{~m}$ zone and the centre of the pitch. But only two of 15 intermediate speed tackles occurred in the $22 \mathrm{~m}$ zones. Heavy impact (crunching or forceful) tackles were equally distributed over the field of play.

\section{Discussion}

Case-control studies in competitive team sports can be carried out by matching injured players in one team with their opposite numbers in the other team. This is particularly important in rugby union where the physical characteristics of players participating in the different positions of a rugby XV may differ quite markedly because of the demands placed on them by the different roles they perform within the team. ${ }^{9}$ The analogy that could be drawn between factors influencing the occurrence of road traffic accidents - reduced visual or psychomotor skills because of the consumption of alcohol, visual impairment, tiredness, or the influence of drugs - and tackle injury episodes cannot be supported by the findings of this survey. ${ }^{10}$ None of the other player related factors examined suggest that they may have contributed either to the tackle injuries that occurred. Nor were match preparation, exposure to tackle practice and coaching, or place in the team implicated. The $95 \%$ confidence intervals for the odds ratio are very wide as a result of the low numbers of matched pairs available for analysis. It was calculated that the study involving 72 tackle injuries had 0.650.89 probability of detecting an adverse or protective effect of 3 -that is, three times the risk 
for those exposed compared with those not exposed to the risk factor. Therefore we are relatively confident that a large effect is not being missed because the number of tackle injuries was not larger. There were insufficient numbers of players to investigate the influence of weather and pitch conditions on tackle injuries.

Considerable public interest has been focused recently on the frustrations experienced by motorists which expresses itself as "road rage". Rugby football is a rugged contact sport in which frustrations occasionally boil over into physical altercations. Is there an equivalent of road rage on the rugby pitch? Administering validated psychomotor questionnaires to players involved in tackle injuries and their matched controls was designed to test the hypothesis that "pitch rage" induced in players may contribute to injuries in the tackle. The case-control method of identifying an injured player and taking as his control the player with a similar position in the opposite team did not reveal differences in aspects of anger trait and anger expression between injured and non-injured players. A more detailed study could ask whether there are aspects of anger trait and expression that characterise tackling or tackled players who were or were not injured. Further, injury rates could be examined to see if they increased or decreased when players with certain personality characteristics were involved in a tackle together. In addition one could ask whether the personality (anger level of the individual) and the situation (tackled or tackling) and the person-person interaction (the respective levels of anger trait and anger expression of the tackling and tackled players) have combined effects on the likelihood of injury.

It has been emphasised by others that the tackle is a phase of play in rugby union football that has no set procedure as is found in other phases of the game such as scrummaging. ${ }^{11}$ It is a time of hard contact, with players moving at speed since the laws of the game were modified to encourage more continuous open play. This survey is the first detailed report of the circumstances of tackles that result in injury. The most striking finding is that more than half of all tackle injury episodes occurred behind the tackled player or within his field of peripheral vision where he might have only been vaguely aware of a potential tackler's movement. In all blind vision tackle injury episodes, either the tackler or the tackled player were moving at running or sprinting speeds. Forceful or crunching tackles that resulted in injury, on the other hand, were head on or more likely to be within the tackled player's range of side vision, particularly on the tackled player's right side. Most stand offs are right handed, and this may be reflected in more three quarter movements starting on the right hand side of the pitch, resulting in more defensive tackles coming within the right hand side of vision of tackling three quarters as the ball is moved along the three quarter line. The prevalence of injury to the player with the lower momentum was very high in the one third of all tackles in which the tackled and tackling players met with differential impact. This emphasises the importance of players gaining momentum again as soon as possible after a completed phase of play in order to reduce the probability of being injured in the next tackle in which they are involved.

There is no evidence from this study to suggest that the wearing of items of protective clothing or equipment would change the frequency or nature of injuries in the tackle. Under certain circumstances, the psychological effect on players who are wearing "protective" clothing or equipment may actually make injuries in the tackle more frequent and/or more severe. This clearly needs to be investigated, particularly if the regulations on the use of protective clothing or equipment are ever reviewed in the future.

Changes in coaching technique or training players to improve their range of peripheral vision may help. But the goal of all concerned with the laws of rugby union football should be to minimise injuries in order to make the game safer and thus more enjoyable for participants. It is the high speed tackles coming in behind the tackled player's line of vision on which attempts to reduce the impact of injuries in the tackle should be focused. However, before this can be addressed, it is essential that information is collected on the circumstances of the vast majority of tackles in an average game of rugby union football where no injury occurs. Only when this comparative information is available for a representative sample of matches, which take into account different playing standards as well as differences in weather and pitch conditions, can rational judgements be made about reducing the impact of injury in the tackle, whilst retaining the running open play that has resulted in the upsurge of popular interest in rugby union football.

We thank the following: all the linkmen of senior rugby clubs affiliated to the SRU who participated in the study; the developaffiliated to the SRU who participated in the study; the develop-
ment officers of the SRU for collating information on the ment officers of the SRU for collating information on the
circumstances of tackles in which injury occurred; Sue Hutton, the survey co-ordinator; Anne Simmons and Patti Pattison for administrative support. The study received financial support from a grant provided by the International Rugby Settlement Trust, administered by the Scottish Rugby Union.

1 Clark DR, Roux C, Noakes TD. A prospective study of the ncidence and nature of injuries to adult rugby players. $S$ Afr Med f 1990;77:559-62.

2 Dalley DR, Laing DR, McCartin PJ. Injuries in rugby football, Christchurch, 1989. New Zealand fournal of Sports Medicine 1991;20:2-5

3 Hughes DC, Fricker PA. A prospective study of injuries to first-grade Rugby Union players. Clinical fournal of Sports Medicine 1994;4:249-56.

4 Garraway WM, Macleod DAD. Epidemiology of rugby football injuries. Lancet 1995;345:1485-7.

5 Messier SP, Pittala KA. Etiologic factors associated with Messier SP, Pittala KA. Etiologic factors associated with
selected running injuries. Med Sci Sports Exerc 1988;20: 501-5.

6 Macera CA, Pate RR, Powell KE, et al. Predicting Macera CA, Pate RR, Powell KE, et al. Predicting
lower-extremity injuries among habitual runners. Arch lower-extremity injuries among

7 Walter SD, Hart LE, McIntosh JM, et al. The Ontario cohort of running-related injuries. Arch Intern Med 1989;149:2561-4.

8 Spielberger CD. State-trait anger expression inventory: revised research edition. Odessa, FL: Psychological Assessment Resources Inc., 1991.

9 Lee AJ, Myers LM, Garraway WM. Influence of player's physique on rugby football injuries. Br $\mathcal{F}$ Sports Med 1997; 31:135-8

10 McCarroll JR, Haddon W. A controlled study of fatal automobile accidents in New York City. Fournal of Chronic Disease 1961;15:811-26.

11 Simpson J, Chalmers D, Waller A, et al, on behalf of the Rugby Injury and Performance Project. Tackling rugby injury: recommendations for reducing injury to rugby union players in New Zealand. Dunedin: Injury Prevention Research Unit and Human Performance Centre, University of Otago, 1994. 